\title{
AVANCES EN EL LIDERAZGO: MARCO DE COMPETENCIAS DE LOS LÍDERES PROFESIONALES
}

\section{Advances in leadership: a competence framework for professional leaders}

\author{
Francisco Javier Gómez GonzÁlez \\ Universidad de Valladolid. Departamento de Sociología y Trabajo Social \\ javier@emp.uva.es
}

Juan José Lacasta Reoyo

Plena inclusión

Vicente Antonio Martínez-Tur

Instituto Universitario de Investigación en Psicología de los Recursos Humanos, del Desarrollo Organizacional y de la Calidad de Vida Laboral-IDOCAL

Carmen RodRíguez SumazA

Universidad de Valladolid. Departamento de Sociología y Trabajo Social

Recepción: 24 de noviembre de 2017

Aceptación definitiva: 17 de abril de 2018

Resumen: Las organizaciones de Plena inclusión y muchas otras del Tercer Sector están en proceso de cambio organizacional porque la orientación a las personas y a la transformación social requiere remover profundamente la cultura, los procesos y la estructura de cada organización. Para que el cambio tenga éxito, el ejercicio de un liderazgo adecuado es crítico. Por ello, en Plena inclusión se ha iniciado un proceso para desarrollar en las personas que dirigen las organizaciones y sus servicios las competencias de liderazgo necesarias para gestionar el cambio. Junto con un equipo de las universidades de Valencia y Valladolid se ha elaborado un marco de competencias para estas personas, como base para la programación posterior de un posgrado. Para ello se celebraron dos sesiones de trabajo, una con gerentes y otra con personal técnico experto en procesos organizacionales. En ambas se identificaron competencias clave y necesidades formativas. 
El resultado final es un marco de competencias de líderes profesionales organizadas en tres ejes -conocimientos, habilidades y actitudes- y cinco niveles: competencias personales, respecto a las personas, los equipos, la organización y el entorno. Dicho marco es la base para organizar los sistemas de aprendizaje y de formación necesarios para formar los y las líderes profesionales que Plena inclusión desea y necesita.

PALABRAS ClAVE: gerencia; personal directivo; competencias; cambio organizacional; aprendizaje.

Авsтract: The organizations of Plena inclusion and many others of the Third Sector are promoting an organizational change because people's orientation and social transformation imply a deeply reform in the culture, the processes and the structure of each organization. The exercise of an adequate leadership is critical to assure a successful change. For this reason, Plena inclusión has started a process to develop the leadership skills needed to manage the change in the people who lead the organizations and their services. A competency framework has been developed for these people with the help of a team from the universities of Valencia and Valladolid. It will be the basis for a future postgraduate program. Two work sessions were held, one with managers and the other with technical staff expert in organizational processes, to identify key competences and training needs. The final result is a framework of competences of professional leaders organized in three dimensions -knowledge, skills and attitudes- and five levels: personal competences, related to people, to teams, to the organization and to the environment. This framework is the basis for organizing the learning and training systems necessary to train the professional leaders that Plena inclusion wants and needs.

KEY WORDS: management; managers; competences; organizational change; learning.

\section{Introducción}

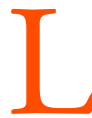

AS ORGANIZACIONES QUE FORMAN PARTE DEL MOVIMIENTO ASOCIATIVO del ámbito de la discapacidad intelectual Plena inclusión, junto con muchas otras entidades del Tercer Sector, están en proceso de cambio organizacional debido a que la orientación a las personas y a la transformación social requiere remover profundamente la cultura, los procesos y la estructura de cada entidad. Para que estos cambios tengan éxito, el ejercicio de un liderazgo adecuado se revela como una cuestión crítica. Por ello, en Plena inclusión se ha iniciado un proceso encaminado a desarrollar, en las personas que dirigen las organizaciones y sus servicios, las competencias de liderazgo que necesitan para gestionar el cambio. El primer producto, elaborado con la Universidad de Valencia y con la Universidad de Valladolid, es un marco de competencias para estas personas, como base para la programación posterior de un posgrado. El objetivo de esta comunicación es presentar este marco de competencias.

En el periodo en que se ha desarrollado la investigación y se ha diseñado el marco de competencias que se describe en el presente trabajo, el Movimiento Asociativo Plena Inclusión elaboraba su V Plan Estratégico 2016-2020, aprobado en Asamblea General de 24 de junio de 2016. Este Plan recoge los resultados de un proceso de participación 
cuyos hitos fundamentales fueron el Foro Consultivo de Oviedo (octubre de 2015) y el Encuentro Guadarrama (enero 2016) y como consecuencia del cual se ha formulado un panel de nueve Horizontes Estratégicos articulados en 65 retos.

Como es lógico, al tratarse de una reflexión de carácter estratégico, el liderazgo asume un papel importante en estos horizontes y retos, si bien tiene un componente claramente transversal puesto que no constituye un horizonte específico, sino que está presente en prácticamente todos ellos. En este sentido, en el Plan se hace referencia a un liderazgo diverso, que integre a las personas con discapacidad (Horizonte 1, Reto 2.1), un liderazgo basado en derechos (Horizonte 8, Reto 3.2) y, especialmente, se señala la necesidad de un modelo de liderazgo compartido con un plan de mejora (Horizonte 6, Reto 5.1).

Este modelo de liderazgo compartido en el Movimiento Plena inclusión lleva asociado, necesariamente, un esfuerzo de formación, ya sea a partir de una ampliación significativa del número de acciones formativas destinadas a directivos sociales a través de la Escuela de En Plena Forma (Horizonte 9, Reto 5.2) o a través de propuestas de postgrado universitario (Horizonte 9, Reto 5.3) (Plena inclusión, 2016).

Con anterioridad a este V Plan, la temática del liderazgo ha estado presente en prácticamente toda la trayectoria de planificación estratégica en la entidad. De hecho, en el I Plan Estratégico de FEAPS aprobado por la Asamblea General Extraordinaria del 19 de abril de 1997 se recogía como eje fundamental el desarrollo organizativo, fundamentado en que "los dirigentes de FEAPS - directivos o técnicos-adquieran un sentido moderno de liderazgo y mejoren en el desempeño de la función directiva” (FEAPS, 1997).

El II Plan (2002-2005), vertebrado alrededor del concepto de calidad, también daba un importante rol al liderazgo, papel que se consolida en el III Plan Estratégico 2006-2009 con el objetivo de "Consolidar un liderazgo comprometido con modelos centrados en las personas y su calidad de vida" y en el IV Plan Estratégico FEAPS (2011-2014), que propone "Fomentar un estilo de liderazgo adecuado a los nuevos retos y al modelo de entidad que se necesita para afrontarlos”, línea de actuación propuesta junto al fomento del "liderazgo basado en valores", y señalando claramente la apuesta por la formación.

Queda clara, por tanto, la decidida apuesta de Plena inclusión por el fomento de un modelo propio de liderazgo, descrito en los cinco planes estratégicos previos bajo los atributos de liderazgo comprometido, de derechos, diverso, por valores, inclusivo, moderno, centrado en personas, centrado en calidad de vida, etc. Este modelo se ha desarrollado en una serie de documentos operativos relacionados con el código de buen gobierno y ha inspirado la formación desarrollada por la entidad. Todo ello se enmarca en el contexto de una exigente apuesta de la entidad por la mejora organizacional (Lacasta 1998a), por el desarrollo de las personas que forman parte del equipo humano de la organización, por la calidad de los servicios que ofrecen (Tamartit, 2015) y por la calidad de vida de los usuarios y usuarias de los mismos (Lacasta, 1998b y 2002).

Partiendo de toda esta trayectoria, en el año 2016 la dirección de Plena inclusión asume como propia la tarea de continuar con la mejora en el ejercicio del liderazgo y 
desde la Dirección de Estrategia y Desarrollo Organizacional se promueve el comienzo de trabajos encaminados a:

1. Elaborar un listado de competencias que describan el perfil del modelo de liderazgo de Plena inclusión.

2. Diseñar contenidos y metodologías docentes que permitieran, a su debido momento, proponer actuaciones de formación interna y de desarrollo de formación de postgrado.

Esta dinámica de trabajo se ha llevado a cabo durante los años 2016-2017, desarrollada de manera conjunta por Plena inclusión, la Universidad de Valencia y la Universidad de Valladolid, estando implicados directamente en el equipo Juan José Lacasta, de Plena inclusión; José María Peiró y Vicente Martínez-Tur, del Instituto de Investigación en Psicología de los RR. HH., del Desarrollo Organizacional y de la Calidad de Vida Laboral (en adelante IDOCAL, de la Universidad de Valencia), junto a Carmen Rodríguez Sumaza y Francisco Javier Gómez González, del Departamento de Sociología y Trabajo Social de la Universidad de Valladolid. En el presente documento se sintetizan algunos de los resultados de este estudio, detallando, en primer lugar, una serie de reflexiones sobre la metodología y, en segundo lugar, describiendo el proceso seguido para determinar las competencias emergentes en materia de liderazgo.

Aunque cada contexto es susceptible de contar con enfoques ad hoc, en la actualidad parecía claro que el modelo para definir y evaluar la actividad laboral debía basarse en el concepto de competencia. Este concepto no es excesivamente antiguo. Mulder (2007) señala como bases fundamentales del enfoque de competencias la obra de McClelland (1973) y apunta que buena parte del éxito de la introducción del concepto de competencia en la estrategia corporativa se debe a la contribución de Prahalad y Hamel (1990).

De hecho, en los años en que se difundió en España la obra de Le Boterf (2001) y Lévy-Leboyer (1997), en el periodo del cambio de siglo, todavía se estaba lejos del declive de conceptos vinculados a la idea tradicional de puesto de trabajo. El éxito contemporáneo de la idea de competencia, como base para comprender y evaluar el desempeño de las personas en su actividad laboral, se ha acabado imponiendo. Se trata de un concepto con una amplia base bibliográfica, de investigación y práctica, y sobre cuya comprensión todavía hay debate. En todo caso, la competencia tiene una naturaleza integradora que combina los conocimientos, las habilidades y las actitudes que son necesarias para la realización efectiva de una actividad laboral (Mateo, Escofet, Martínez-Olmo, Ventura y Vlachopoulos, 2012).

En Europa, el proyecto Tuning tuvo una enorme incidencia en la definición de necesidades de formación en las titulaciones del Espacio Europeo de Educación Superior y es el responsable de que en la práctica totalidad de la enseñanza reglada universitaria las competencias sean el referente en la evaluación de necesidades, en el diseño y en la evaluación. Según Tuning los resultados del aprendizaje "se expresan en términos de competencia”, siendo estas "una combinación dinámica de conocimientos, habilidades, capacidades y valores” (González y Wagenaar, 2006: 4). Por otra parte, los procesos de evaluación de competencias profesionales desarrollados 
desde el CEDEFOP también dotan de un gran protagonismo a la competencia como unidad de medición y evaluación (CEDEFOP, 2016).

2. Método: Sistemática de evaluación de necesidades de formación para el liderazgo en Plena inclusión

Partiendo del protagonismo de las competencias como unidad de análisis, el equipo de trabajo planteó como objetivo fundamental del estudio determinar el perfil competencial deseado para un ejercicio eficaz del liderazgo en las organizaciones del Tercer Sector y, específicamente, de Plena inclusión. Estas competencias deberán facilitar el desempeño de un liderazgo coherente con los valores fundamentales de este sector, con las exigencias de su entorno y con su finalidad institucional. Subyace en este empeño la idea de que solo una organización verdaderamente comprometida con la mejora continua de la calidad se preocupa por disponer de profesionales capacitados para abanderar iniciativas que promuevan cambios significativos para sus usuarios y para sus profesionales, las "mejores prácticas” en el sentido de promover la eficacia y la eficiencia de la organización a la vez que incidir en el bienestar de las personas que la componen (Schalock, 2015).

En el desarrollo de este objetivo, no se partía de una hipótesis de trabajo cerrada, pero en su primera concepción se planteaba la suposición de que la percepción de las competencias de liderazgo variaría en función de los actores. También se asumía como hipótesis el hecho del incremento de las competencias relacionales sobre las competencias instrumentales, si bien este hecho suscitaba un fuerte debate.

La metodología empleada se basaba en metodologías de detección de necesidades de carácter participativo y pluralista, que han combinado un análisis experto general (análisis de la literatura académica) y un análisis experto participativo (consulta a los perfiles directivos y al personal técnico de apoyo al ejercicio de liderazgo).

En este sentido, el sujeto de estudio para el trabajo fueron, por un lado, personas con cargos directivos y puestos gerenciales de entidades del sector de organizaciones de personas con discapacidad intelectual y, por otro lado, el personal técnico de alto nivel encargado de funciones transversales en el Movimiento Asociativo.

Respecto a los procedimientos, en la evaluación de necesidades de formación se integran diferentes fuentes de información: (1) análisis prospectivo sobre las tendencias de cambio en el liderazgo; (2) el benchmarking; (3) la planificación estratégica de los recursos humanos y otros documentos de gobernanza interna de las organizaciones, y (4) la detección participativa de necesidades de formación.

El núcleo fundamental del presente trabajo ha sido el de las actuaciones relacionadas con la detección participativa de necesidades debido a que la apuesta metodológica ha sido dotar de protagonismo a la dimensión participativa y utilizar los análisis técnicos y de benchmarking como información para el debate de los grupos o la mejora terminológica y conceptual de los resultados del trabajo en grupo. No obstante, y a modo de síntesis, en los siguientes epígrafes también se comentarán los fundamentos del análisis prospectivo, el benchmarking y la planificación estratégica como inspiradores del nuevo perfil de líder. 


\subsection{Análisis prospectivo de las tendencias de cambio en el ejercicio del liderazgo}

La formación se caracteriza por ser un ejercicio de futuro realizado desde los conocimientos adquiridos en el pasado. Para dotar al diseño formativo de este carácter prospectivo es necesario hacer una profunda reflexión sobre los cambios probables y/o deseables. En este sentido, seguramente hay pocos sectores tan proclives a la predicción como el pensamiento sobre el liderazgo. Publicaciones como la coordinada por Hesselbein, Goldsmith y Beckhard (2004), titulada El lider del futuro y publicada por la Fundación Drucker, son ejemplos paradigmáticos de este tipo de reflexión que ha generado una pléyade de obras del pensamiento organizativo sobre las competencias emergentes en materia de liderazgo o sobre las características de estos líderes, ya sea apoyando estos análisis en supuestos datos empíricos o, simplemente, expresando las propias convicciones como si fueran evidencias científicas. Así, se hace referencia a las Siete lecciones para los líderes del futuro en la obra de Kouzes y Posner (2004), mientras Covey (2004) apuntaba los tres papeles del líder en el nuevo paradigma. Pareciera que las obras de pensamiento no pueden evitar recurrir a la enumeración, para enfatizar el carácter cuasi revelado de sus propuestas, como si fueran los nuevos mandamientos.

Lógicamente, el Tercer Sector no escapa a esta dinámica y, aunque con una producción de literatura manifiestamente menor, también presenta publicaciones de pensamiento sobre el/la líder del futuro. Existen monográficos específicamente centrados en el liderazgo de entidades no lucrativas, siendo relevantes los manuales de Dym y Hutson de 2005 o de Tirmizi y Vogelsang de 2017, si bien presentan el problema de referirse específicamente a la experiencia norteamericana que, en términos de configuración del Tercer Sector, cuenta con marcadas singularidades respecto a la situación de España.

La consulta de estos materiales ayuda a analizar campos emergentes, pero, en todo caso, parece que en el campo de los perfiles de liderazgo la clave no es valorar cómo van a ser los líderes del futuro, sino pensar en cómo deseamos que sean. En este sentido el matiz entre los términos ingleses de forecasting y foresight puede ser esclarecedor, puesto que aunque ambos implican un ejercicio de prospectiva, en el caso del forecasting se hace referencia a una prolongación de las tendencias como forma de prever el futuro, mientras que el foresight se entiende como una evaluación del futuro incluyendo propuestas de actuación para construirlo.

En el caso que nos ocupa, referido a Plena inclusión, no resulta tan importante definir cómo serán los y las líderes, sino determinar cómo deseamos que sean, reflexionando, eso sí, sobre las características del contexto al que deberán adaptarse y/o sobre el que tendrán que incidir.

\subsection{El benchmarking: análisis de la oferta de formación para el liderazgo en el Tercer Sector}

La formación directiva en el Tercer Sector es un sector maduro que cuenta con un conjunto importante de iniciativas suficientemente diversas como para permitir realizar una copia creativa (benchmarking) de las propuestas existentes. 
Asumiendo que la formación para el liderazgo es equiparable con el nivel máster, el análisis de la oferta formativa ha permitido detectar tres tipos de modelos de enseñanza:

a) Ofertas articuladas como Master in Business Administration que cuentan con una estructura muy estandarizada y un peso relevante de las materias de corte económico y regulatorio. El enfoque de estos MBA abarca desde opciones muy instrumentales a opciones de carácter más globalizador y estratégico. Habitualmente son impartidas por escuelas de negocios privadas.

b) Ofertas centradas en la gestión de entidades no lucrativas, generalmente másteres, que intentan integrar la especificidad del sector social y las normas generales de gestión. Se trata de ofertas como el Master en Administración y Dirección de Fundaciones, Asociaciones y otras Entidades no Lucrativas de la Universidad Autónoma de Madrid; el Master en Dirección y Gestión de Entidades no Lucrativas de la Universitat Oberta de Catalunya; el de Gestión Directiva de Organizaciones no Lucrativas de la UNED; el Curso Especialista en Promoción y Gestión de ONG en la Universidad Complutense de Madrid, o el Máster en economía social y entidades sin ánimo de lucro de la Universidad de Barcelona, todos ellos másteres oficiales o títulos propios de las Universidades públicas y que se complementan con alguna oferta de iniciativa privada como el Máster de Dirección y Gestión de ONG del ESADE Business School.

c) Ofertas centradas en temáticas que comparten el enfoque organizativo de Plena inclusión, aunque no están centrados en la formación de roles directivos. Sería el caso del Master Universitario Erasmus Mundus en Psicología del Trabajo, de las Organizaciones y de los Recursos Humanos del IDOCAL de la Universidad de Valencia y el Master en Consultoría y Gestión de Procesos de Desarrollo Organizativo de la Universidad de Valladolid, pertenecientes ambos a grupos de trabajo que han contado con una relación estrecha con Plena inclusión y que comparten parte de su enfoque en la comprensión de los procesos organizativos.

La comparativa entre estos másteres ilustraba muy bien la existencia de dos alternativas que exigen optar entre un perfil de líder muy orientado hacia competencias instrumentales en materia de gestión económica y conocimiento de la regulación (enfoque más parecido a un MBA) o líderes más atentos a la dimensión social y cuya visión está muy orientada a las singularidades de las organizaciones no lucrativas. Lógicamente, ninguno de los dos modelos son puros, puesto que hay muchos niveles intermedios, pero esta tensión entre líderes económico/jurídicos y líderes de carácter social parece estar presente en el debate del Tercer Sector.

En este sentido, en el presente proceso de detección de necesidades no se llegó a tomar una postura en este debate, prefiriéndose que fueran el personal técnico y las personas con cargos directivos los que llegaran a una postura común. El resultado, como se verá con posterioridad, supone una cierta posición intermedia, pero basculando claramente hacia lo social. Como diría Henry Mintzberg en su conocida obra Managers, not $M B A$ s, el reto consiste en desarrollar directivos y directivas que practiquen a partir de sus propias experiencias (Mintzberg, 2004). 
2.3. El modelo de liderazgo existente en la planificación estratégica y otros documentos de gobernanza de Plena inclusión

Para analizar el ejercicio del liderazgo y la definición de perfiles y competencias es muy relevante contar con documentos internos que permitan determinar qué tipo de principios regulan esta función. En el caso del presente estudio fue el Código de Buen Gobierno del Movimiento Asociativo FEAPS (2014) el inspirador de los valores y principios generales que regulan la actuación de los y las líderes de las entidades. Este documento recoge como principios básicos los siguientes:

- Principio 1: Coberencia con la misión y el marco ético de FEAPS. Gobierno de las organizaciones orientado a la persona y a la transformación social, en coherencia con nuestra misión, nuestro compromiso ético y nuestro proyecto común.

- Principio 2: Democracia, gobernanza y participación de los grupos de interés. Sistema de gobernanza basado en la participación de los grupos de interés en las decisiones que les afectan y en la concepción de nuestras organizaciones como instituciones democráticas.

- Principio 3: Gestión responsable, honesta y comprometida con el proyecto común. Ejercicio del gobierno y la gestión de las organizaciones según los principios y valores compartidos que configuran nuestro proyecto común al servicio de las personas y la sociedad.

- Principio 4: Transparencia y veracidad. Rendición de cuentas a nuestros grupos de interés desde la transparencia en todas sus dimensiones y la difusión de información siempre veraz.

También son muy ilustrativos del modelo de liderazgo de Plena inclusión aquellos documentos que recogen el enfoque de la formación a personal directivo que se ha desarrollado hasta la actualidad. En el año 2016 el Curso Básico de Formación de Personas Directivas en Plena inclusión estaba articulado en objetivos y contenidos, no definía claramente competencias y presentaba un enfoque de la formación muy orientado a los procesos de cambio organizativo.

Esta oferta formativa cuenta con una estructura que ilustra muy bien los diversos niveles que implican a un/a líder en este sector y que está formada por un Módulo 0: Introducción; Módulo 1: Cultura y proyecto común del movimiento asociativo Plena Inclusión; Módulo 2: Las personas; Módulo 3: Nuestras organizaciones y el modelo de organización que necesitamos; Módulo 4: Incidencia política y social; Módulo 5: El papel de los personas directivas: liderazgo y poder; y Módulo 6: Procesos y herramientas para que las personas directivas trabajen y avancen: el futuro. Se trata de un enfoque que transmite claramente el deseo de unificar un modelo de liderazgo con una clara orientación al entorno.

Por último, fue especialmente relevante para el presente trabajo la definición de horizontes señalada en el V Plan Estratégico de Plena inclusión que define, de manera tanto directa como indirecta, el conjunto de retos que debe asumir el liderazgo. Estos horizontes se reflejan en la Tabla 1. 


\section{Tabla 1. Horizontes del V Plan Estratégico de Plena Inclusión}

Horizonte 1. Apuesta radical por la plena ciudadanía

Horizonte 2. Fomentar una política de apoyo a familias desde un enfoque centrado en la familia

Horizonte 3. Reivindicar un nuevo marco jurídico que garantice e impulse la vida de las personas y la de sus familias

Horizonte 4. Potenciar una práctica de trabajo colaborativo. En red, en alianza

Horizonte 5. Apostar por los procesos de transformación de entidades y servicios. Avanzar desde nuestro sentido de la calidad

Horizonte 6. Afrontar la renovación y el cambio generacional desde una visión moderna del asociacionismo

Horizonte 7. Aumentar la visibilidad social del colectivo

Horizonte 8. Coordinar y articular la defensa de los derechos y nuestra acción de prestadores de apoyo

Horizonte 9. Aumentar nuestra coordinación y la acción conjunta para afrontar los retos en común

\subsection{La detección participativa de necesidades de formación}

Partiendo de la documentación generada en el análisis de documentos internos, los análisis de prospectiva y el benchmarking de la oferta formativa del sector, se consideró que para explorar la inclinación por las posibles alternativas generadas sobre el enfoque y de cara a elaborar una propuesta de perfil que pudiera ser aceptada por las personas del Movimiento Asociativo Plena inclusión y del Tercer Sector, era fundamental establecer algún tipo de dinámica participativa. Para ello se establecieron dos tipos de perfiles:

a) Gerentes de entidades de Plena inclusión, actualmente en ejercicio, que configuraron una muestra diversa en cuanto a procedencia geográfica, tipología de entidad y perfil formativo de base.

b) Personal técnico y directivo de Plena inclusión, tanto de las oficinas de Plena Inclusión España como de alguna de las federaciones autonómicas.

La sesión de trabajo para la detección de competencias y capacidades de los y las gerentes fue llevada a cabo el 15 de junio con la asistencia de 13 personas y simultáneamente se llevaba a cabo la reunión de 15 técnicos/as y directivos/as. El trabajo se realizó a partir de dinámicas estructuradas (Metaplan) o semiestructuradas (DAFO y rondas de intervención), como se observa en la Tabla 2.

\begin{tabular}{|l|l|l|}
\hline \multicolumn{2}{|c|}{ Tabla 2. Metodología de las reuniones de detección de necesidades } \\
\hline \multicolumn{1}{|c|}{ Contenido } & Metodología/actividad & \multicolumn{1}{c|}{ Observaciones } \\
\hline $\begin{array}{l}\text { Las necesidades } \\
\text { de los y las líderes } \\
\text { del TS del futuro }\end{array}$ & $\begin{array}{l}\text { Metaplan } \\
\text { Trabajo grupal }\end{array}$ & $\begin{array}{l}\text { Énfasis en las competencias, y ver cómo se } \\
\text { traducen en contenidos o materias formativas. } \\
\text { Concretar qué materias y qué metodologías }\end{array}$ \\
\hline
\end{tabular}

Ediciones Universidad de Salamanca / CC BY-NC-ND

Siglo Cero, vol. 49 (4), n. ${ }^{\circ} 268,2018$, octubre-diciembre, pp. 7-34 


\section{TABLA 2. Metodología de las reuniones de detección de necesidades (cont.)}

\begin{tabular}{|l|l|l|}
\hline \multicolumn{1}{|c|}{ Contenido } & Metodología/actividad & \multicolumn{1}{c|}{ Observaciones } \\
\hline $\begin{array}{l}\text { La oportunidad/ } \\
\text { pertinencia de la } \\
\text { formación: retos } \\
\text { y obstáculos }\end{array}$ & $\begin{array}{l}\text { DAFO } \\
\text { Trabajo grupal }\end{array}$ & $\begin{array}{l}\text { Averiguar puntos reto, puntos palanca, obs- } \\
\text { táculos y resistencias, oportunidades... }\end{array}$ \\
\hline
\end{tabular}

3. Resultados del trabajo: marco de competencias para el liderazgo en Plena inclusión y en el Tercer Sector

Después del trabajo del grupo de discusión, en la Tabla 3 se recoge el listado de temas recurrentes sobre los que había consenso por parte de los gerentes en relación con las competencias que deben tener los y las líderes del futuro en las entidades para personas con discapacidad y en el Tercer Sector.

Se recogen las ideas fundamentales en su formulación rápida sin incorporar la redacción característica del concepto de competencias.

\begin{tabular}{|l|l|}
\hline \multicolumn{2}{|c|}{$\begin{array}{c}\text { TABLA 3. Competencias que deben tener los y las líderes del futuro } \\
\text { propuestas por gerentes de entidades de personas con discapacidad) }\end{array}$} \\
\hline Visión estratégica & Liderazgo \\
\hline Evaluar/ver grupos de interés & Motivar-soñar \\
\hline Manejo de indicadores & Gestión de personas (perspectiva psicológica) \\
\hline Innovación & Mostrarse carismático \\
\hline Gestionar grupos de interés & Desarrollo de otras personas \\
\hline Visión a medio plazo & Autoconocimiento \\
\hline Planificación estratégica & Trabajo en equipo \\
\hline Versatilidad & Delegar \\
\hline Valoración del entorno & Motivar \\
\hline Visión de futuro & Crear equipo \\
\hline Ética/derechos de las personas & Liderar \\
\hline Gestión eficaz y eficiente & Captación talento y desarrollo de otros \\
\hline Todo lo relativo a la gestión económica & Flexibilidad \\
\hline Manejo de la legislación & Gestión económica \\
\hline $\begin{array}{l}\text { Principio de realidad aunque también } \\
\text { se sueñe }\end{array}$ & $\begin{array}{l}\text { Gestión sostenible y búsqueda de fondos } \\
\text { /recursos }\end{array}$ \\
\hline Enfoque sistemático & Manejo de normativas \\
\hline Trazabilidad & Anticipación, gestión de cambios \\
\hline Manejo de procesos & Orientación hacia la excelencia \\
\hline Uso de nuevas tecnologías & Hacia la persona \\
\hline
\end{tabular}

Ediciones Universidad de Salamanca / CC BY-NC-ND

Siglo Cero, vol. 49 (4), n. ${ }^{\circ} 268,2018$, octubre-diciembre, pp. 7-34

$$
-16-
$$




\section{TABLA 3. Competencias que deben tener los y las líderes del futuro} (propuestas por gerentes de entidades de personas con discapacidad) (cont.)

\begin{tabular}{|l|l|}
\hline Habilidades comunicativas & Modelo de calidad de vida \\
\hline Hablar en público-visibilidad & Gestión de la calidad \\
\hline Comunicación interna-externa & Entorno \\
\hline & Alianzas y tecnologías en red \\
\hline & Responsabilidad social corporativa \\
\hline
\end{tabular}

En un segundo momento se abordó el análisis de contenidos. Es llamativa la similitud entre la Tabla 3 y la Tabla 4. Esto se debe a que, aunque en Plena inclusión se maneja de manera habitual el término de competencia y se trata de un concepto cada vez mejor comprendido, en la práctica es muy difícil diferenciar entre competencias y conocimientos, en parte porque las competencias tienen, a su vez, dimensiones cognitivas. Por este motivo, la tabla segunda, que recoge los resultados de la pregunta sobre conocimientos que deberían tener los y las líderes del futuro, reitera en alguna ocasión el contenido de la tabla anterior.

\begin{tabular}{|l|l|}
\hline \multicolumn{2}{|c|}{$\begin{array}{c}\text { TABLA 4. Contenidos que deben figurar en una formación para el desarrollo } \\
\text { del liderazgo (propuestas de los y las gerentes de entidades de personas } \\
\text { con discapacidad) }\end{array}$} \\
\hline Estrategia, visión & Orientación a la excelencia \\
\hline Gestión de procesos & Calidad de vida \\
\hline Planificación estratégica & Modelos de calidad (EFQM, ISO...) \\
\hline Evaluación, indicadores y resultados & Buenas prácticas e intercambios \\
\hline $\begin{array}{l}\text { Ética y código de buen gobierno (buenas } \\
\text { prácticas, transparencia...) }\end{array}$ & Trabajo en equipo y desarrollo de personas \\
\hline $\begin{array}{l}\text { Reivindicación de derechos y aplicación de } \\
\text { convención de la ONU }\end{array}$ & Desarrollo de otros \\
\hline Comunicación & Técnicas de motivación \\
\hline Plan de comunicación & Gestión de personas y del conocimiento \\
\hline Comunicación interna y externa & Clima laboral \\
\hline $\begin{array}{l}\text { Competencia individual (p. e., habla en } \\
\text { público) }\end{array}$ & Gestión del estrés \\
\hline Comunicación con grupos de interés & Conflictos \\
\hline $\begin{array}{l}\text { Protocolos y estrategias de comunicación } \\
\text { (visibilidad) }\end{array}$ & Gestión del tiempo \\
\hline Nuevas técnicas de marketing & Gestión de equipos \\
\hline Alianzas y trabajo en red & $\begin{array}{l}\text { Gestión de talento (adquisición y retención, } \\
\text { sucesión, transiciones) }\end{array}$ \\
\hline Responsabilidad social corporativa & Inteligencia emocional, psicología positiva \\
\hline Estructura y roles para la comunicación & Nóminas, convenios \\
\hline
\end{tabular}

Ediciones Universidad de Salamanca / CC BY-NC-ND

Siglo Cero, vol. 49 (4), n. ${ }^{\circ}$ 268, 2018, octubre-diciembre, pp. 7-34 


\begin{tabular}{|l|l|}
\hline \multicolumn{2}{|c|}{$\begin{array}{c}\text { TABLA 4. Contenidos que deben figurar en una formación para el desarrollo } \\
\text { del liderazgo (propuestas de los y las gerentes de entidades de personas } \\
\text { con discapacidad) (cont.) }\end{array}$} \\
\hline Gestión de la marca y legitimación & $\begin{array}{l}\text { Otros contenidos que consideraron } \\
\text { relevantes }\end{array}$ \\
\hline Flexibilidad/sostenibilidad & Liderazgo \\
\hline $\begin{array}{l}\text { Gestión económica (elaboración de los dife- } \\
\text { rentes aspectos) }\end{array}$ & Nuevas tecnologías \\
\hline Captación de fondos & Elaboración de proyectos \\
\hline Entorno (detección de necesidades y retos) & Gestión del cambio \\
\hline Influencia en el entorno & Gestión por competencias \\
\hline $\begin{array}{l}\text { Normativa y legislación (derecho civil, ley } \\
\text { de transparencia, mercantil, prevención...) }\end{array}$ & Visión, misión, valores \\
\hline Recursos comunitarios y visión sistémica & \\
\hline Colaboración (voluntariado...) & \\
\hline
\end{tabular}

En la metodología empleada, la siguiente pregunta planteada a los y las gerentes indagaba qué necesidades de formación experimentan en su día a día particular (nivel individual). A partir de sus respuestas se pudo profundizar en cuestiones específicas, ya que explora necesidades concretas que estas personas viven a diario. La idea general de esta pregunta es establecer un diálogo entre las opiniones que los y las gerentes expresan con carácter general y las experiencias propiamente individuales. En este caso la diversidad de respuestas es muy amplia y ofrece cierta dificultad su clasificación, motivo por el cual se recogen de manera íntegra en la Tabla 5.

\section{TABLA 5. Necesidades de formación que los y las gerentes experimentan en su día a día particular (nivel individual)}

\begin{tabular}{|l|l|}
\hline $\begin{array}{l}\text { Manejo de fuentes de financiación (proyectos } \\
\text { y marketing) }\end{array}$ & $\begin{array}{l}\text { Conocer experiencias de éxito, tanto estatales } \\
\text { como internacionales }\end{array}$ \\
\hline Manejo de comunicación y redes sociales & Transparencia y buen gobierno \\
\hline $\begin{array}{l}\text { Repaso y actualización de nociones económi- } \\
\text { cas de gestión aplicadas a entidades sociales }\end{array}$ & $\begin{array}{l}\text { Módulo importante sobre ética y derechos, } \\
\text { pero aplicados }\end{array}$ \\
\hline Evaluación y rendición de resultados (calidad) & $\begin{array}{l}\text { Liderazgo y gestión del cambio. Alineación } \\
\text { de personas según misión, visión y valores }\end{array}$ \\
\hline Gestión económica & Marketing y comunicación \\
\hline Captación de fondos & La comunicación como competencia personal \\
\hline $\begin{array}{l}\text { Visión estratégica: planificación, resultados } \\
\text { esperados (indicadores), conocer entorno y } \\
\text { que el entorno nos conozca (alianzas, siner- } \\
\text { gias), definir proyectos, visión de futuro (pre- } \\
\text { visión), evaluación de resultados, innovar, } \\
\text { ética y reivindicación de derechos }\end{array}$ & \begin{tabular}{l} 
Herramientas de seguimiento de proyectón. Indicadores eficaces \\
\hline
\end{tabular} \\
\hline
\end{tabular}




\section{TABLA 5. Necesidades de formación que los y las gerentes experimentan en su día a día particular (nivel individual) (cont.)}

\begin{tabular}{|l|l|}
\hline $\begin{array}{l}\text { Flexibilidad: anticipación a cambios, adapta- } \\
\text { ción, sostenibilidad y gestión económica, ac- } \\
\text { tualización de normativa }\end{array}$ & $\begin{array}{l}\text { Autoconocimiento: a nivel emocional, auto- } \\
\text { control, gestiones de relaciones positivas y } \\
\text { negativas, humildad }\end{array}$ \\
\hline $\begin{array}{l}\text { Modelos de intervención en las personas con } \\
\text { discapacidad intelectual }\end{array}$ & $\begin{array}{l}\text { Encontrar una línea común servicio con plano } \\
\text { directivo }\end{array}$ \\
\hline $\begin{array}{l}\text { Comunicación: interna/externa, visibilidad, } \\
\text { alianzas, posicionamiento en el entorno, res- } \\
\text { ponsabilidad social corporativa }\end{array}$ & $\begin{array}{l}\text { Compartir para poder establecer alianzas que } \\
\text { ayuden a realizar lo que pretendemos }\end{array}$ \\
\hline $\begin{array}{l}\text { Orientación a la excelencia: orientación a la la } \\
\text { persona, modelos de calidad de vida }\end{array}$ & $\begin{array}{l}\text { Adaptación de legislación laboral a una buena } \\
\text { gestión de personas, práctica y eficaz }\end{array}$ \\
\hline $\begin{array}{l}\text { Saber qué se espera del trabajo que estoy rea- } \\
\text { lizando, en este proceso de liderazgo... }\end{array}$ & $\begin{array}{l}\text { Trabajo en equipo: hacer equipo, motivación, } \\
\text { liderazgo, saber delegar, gestión de captación } \\
\text { del talento, desarrollo de otros }\end{array}$ \\
\hline Vender a largo & Negociación como habilidad \\
\hline Delegación & Gestión del cambio \\
\hline Gestión del tiempo & \\
\hline
\end{tabular}

La reflexión sobre las competencias está también vinculada con una serie de opiniones formuladas por los y las gerentes en relación con el tipo de formación necesaria para desarrollar estas competencias. En este sentido, hay aportaciones relacionadas con el orden y el rigor: "Seriedad y formación basada en el rigor y la evidencia", señalando que los cursos sean "Estructurados y sistemáticos”, referencias a la personalización de la formación: “Tener en cuenta los perfiles de los participantes” y, llegado el caso, a la necesidad de diversificar la oferta con la "Posibilidad de pensar en especialidades".

Junto a estos temas las demandas más claras de los y las gerentes en relación con la formación atienden al deseo de trabajo cooperativo. "Crear espacios de aprendizaje con cooperación", "Facilitar el intercambio de buenas prácticas dentro del grupo", “Trabajo en equipo (estudiantes como docentes)”, presentación de "Casos y problemas” y "Presentación de buenas prácticas y gestión del conocimiento”. Estas referencias a la dimensión social de la formación atienden al hecho de que la formación de líderes se debe desarrollar incrementando el capital social del alumnado y fomentando un trabajo en red que, con posterioridad, puede ser también beneficioso para todo el movimiento asociativo vinculado a personas con discapacidad y al Tercer Sector en general.

Otros aspectos comentados como deseables para la formación son el desarrollo de "Visitas a centros del sector y a empresas de fuera del sector (apertura a otros sectores)", el empleo de “Tutorías con uso de nuevas tecnologías” y el "Enfoque práctico pero sin perder de vista lo positivo de la clase magistral. Adaptado, en cualquier caso, a la particularidad de la materia”. Como se puede comprobar, la apuesta por lo nuevo y la defensa de modelos previos conviven sin demasiados problemas en las expectativas. 
La visión del personal técnico y directivo de Plena inclusión, experto en procesos organizacionales, tanto del movimiento asociativo en su conjunto como de la Oficina Central, queda recogida en la Tabla 6 y el Gráfico 1. Se trata de una serie de respuestas a preguntas semejantes a las planteadas a los y las gerentes, aunque más simplificadas (solo se preguntó sobre las competencias que valoran necesarias para el desempeño de sus funciones). En la Tabla 6 se señalan las competencias propuestas por este grupo de técnicos y en el Gráfico 1 los niveles de articulación que estructuran las competencias para el liderazgo, según este mismo grupo.

\section{TABLA 6. Competencias que propone el personal técnico}

\section{Líder}

Ser divertido, empático, cercano y facilitador

Personas coherentes y que defienden el valor de las personas. Abiertos a otros entornos, vivencias y prácticas

Sentido de la responsabilidad y del compromiso con las personas, los grupos y la organización

Negociar/motivar

Hacer como líder. Haciendo y mostrando como ejemplo. Al lado

Ser ejemplar. Colaborador

Conocer el modelo de organización necesaria, visión organizativa

Gestión de equipos. Dinámica, emociones. De las personas cuando se reúnen para enfrentar determinado proyecto

Cercano a las personas

Fomentar el desarrollo del talento

\section{Creando red}

Economía del bien común. Cambios sociales, económicos y medioambientales

Asesor económico financiero

Garante de la sostenibilidad

Conocedor de los impulsos organizacionales

Compañero en toma de decisiones viables

Visión de futuro respecto al entorno, Innovación

Liderazgo técnico del proyecto

\section{Conocimiento del medio}

Conocer "casi todo" pero desde la atención directa. Enfoque visión desde la persona

Conocimiento del marco legislativo y jurídico

\section{Innovación y creatividad}

Ser imaginativo 


\section{TABLA 6. Competencias que propone el personal técnico}

Liderazgo visionario

Ver más allá/donde otros no ven

Orientación a la innovación. En lugar de orientación a resultados

Promotor del aprendizaje organizacional en base a la experiencia

Nuevos modelos de negocio y emprendimiento

Saber elaborar planes de viabilidad y sostenibilidad

Análisis de resultados y medición de resultados

Capacidad de diseñar proyectos compartidos con entidades del Tercer Sector que no estén dedicadas a las personas con discapacidad

Saber de cuentas y números

Valores y ética

Ser coherente. Predicar con el ejemplo

Conectado con las personas con discapacidad intelectual y sus familias

Comportamiento basado en valores. Referencia en su manera de ser y relacionarse

Disponibilidad para acercarse a realidades concretas de personas con discapacidad intelectual y sus familias (convivir)

\section{Transformación y flexibilidad}

Transformación organizativa. Catalizador y movilizador de inquietudes para evolucionar en cultura organizativa

Análisis mercado. Oportunidades del entorno. Lograr un ciclo que vaya del análisis del entorno al modelo de negocio, de este a la definición de servicios, de esto a una mayor visibilidad y de esta a una modificación del entorno

Ser más flexible y menos dogmático

Saber gestionar la flexibilidad y la incoherencia

Capacidad de adaptarse a colaborar con equipos en contextos muy diferentes

\section{Desarrollar personas}

Saber negociar

Tener empatía

Saber liderar grupos

Ser didáctico. Saber enseñar

Asertividad

Influencia: conector y generador de alianzas con el entorno

Conectividad con el entorno. Capacidad relacional para generar valor

Conocer de manera concreta y global el entorno donde influye o le influye en su entidad

Conectado con la comunidad. Experto en alianzas comunitarias. Local 


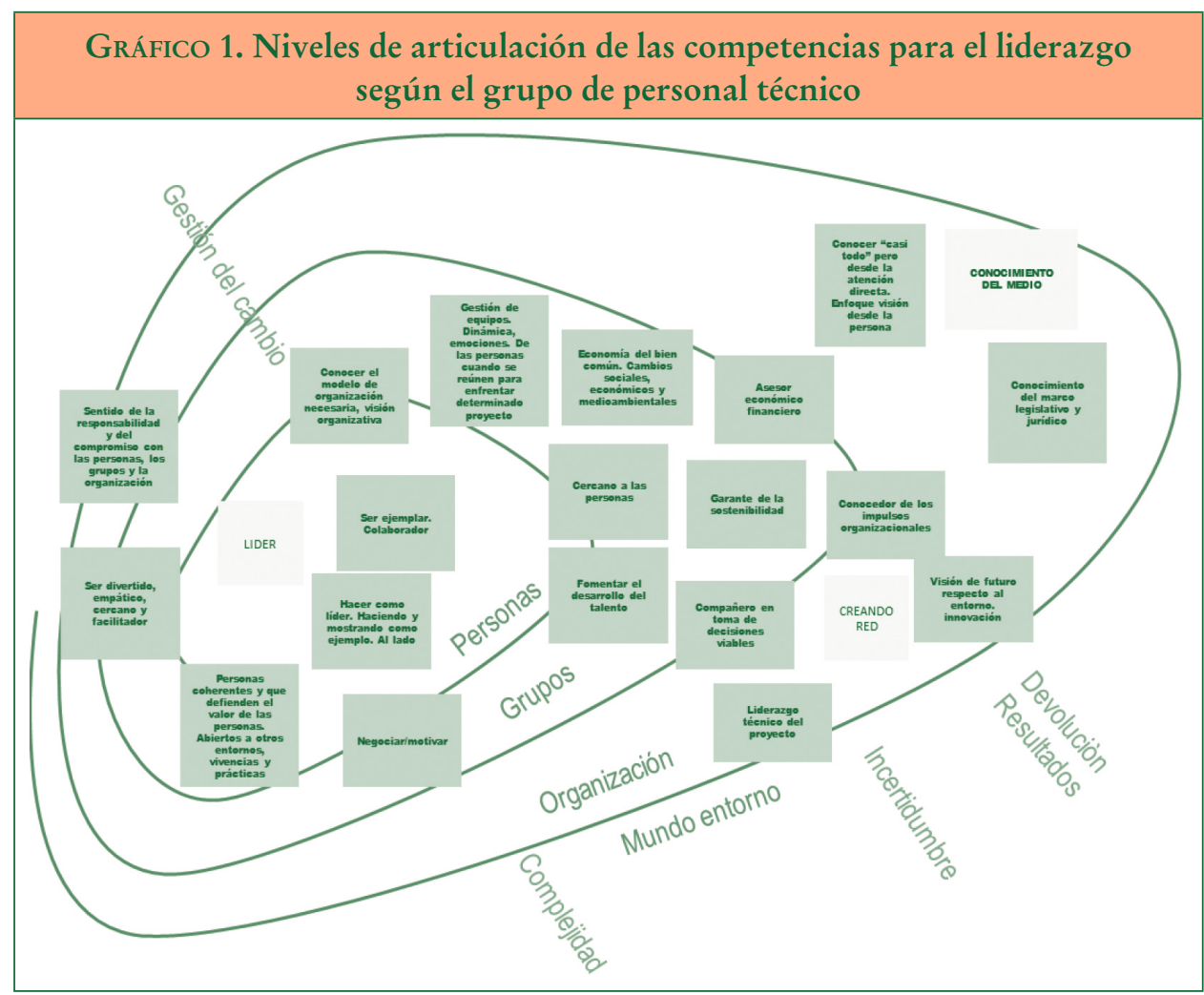

El comentario de los resultados se realiza en un triple nivel de comparación que incluye:

a) Diferencias entre el enfoque que tienen los y las gerentes respecto a las competencias que necesitan individualmente y las que creen que necesitan el resto de gerentes.

b) Diferencias entre las competencias percibidas por los y las gerentes y por el personal directivo y técnico de la Confederación.

c) Diferencias entre las competencias expresadas por estos dos grupos y los enfoques propuestos desde los documentos de planificación estratégica de Plena inclusión.

Sin entrar en un análisis pormenorizado, es significativo que las competencias que los y las gerentes dicen necesitar en primera persona son bastante semejantes a las que perciben como necesarias para el resto de gerentes. Acaso se puede detectar una mayor presencia de habilidades comunicativas; algún aspecto de gestión de estrés y agenda, y la presencia más generalizada de referencias al conocimiento económico, de captación de fondos y regulatorio en el caso de las necesidades individuales. Parece que los y las gerentes se sienten moderadamente seguros en el manejo de procesos 
estratégicos y operativos, pero perciben inseguridad personal en los temas jurídicoeconómicos y en la gestión de su propia agenda de trabajo.

El debate sobre la centralidad de la formación económica y en materias legales es continuo en el curso de la interacción grupal. Parece que los y las gerentes lo perciben como un saber posicional, de manera que se puede funcionar sin él, pero también está dotado de un prestigio y un rigor que refuerza el desempeño de su rol ejecutivo.

La comparativa entre la perspectiva del personal técnico y los y las gerentes refleja, simplificando mucho, la distancia entre un pensamiento estratégico y un enfoque más táctico. El personal técnico de la Federación incorpora más competencias de conocimiento y análisis del entorno, de innovación y de desarrollo de alianzas. Ello anima a una perspectiva hacia afuera, mientras que la visión de los y las gerentes expresa una perspectiva hacia dentro.

En relación con los valores de la organización y las competencias señaladas por personal técnico y gerentes, no se percibe ninguna contradicción significativa, si bien es posible detectar que las competencias del líder, tal y como se percibe en los documentos de la Confederación, atiende más a un modelo estratégico, orientado al cambio, la incidencia social y la relación con el exterior que a un modelo hacia adentro. En todo caso, esto se puede deber a que la buena gestión rutinaria de las organizaciones se considera un trabajo ya conseguido y la apuesta del Movimiento Plena inclusión es hacia un liderazgo más abierto al exterior.

Esta comparación, planteada de manera muy genérica, fue desarrollada por el equipo de trabajo con un formato de comparación de contenidos, que queda recogido en la Tabla 7, basado en la definición de categorías y dimensiones competenciales inferidas a partir de las propias respuestas recogidas en los grupos.

\begin{tabular}{|c|c|c|c|c|c|}
\hline \multicolumn{6}{|c|}{$\begin{array}{l}\text { TABLA 7. Comparativa de las grandes categorías de retos, competencias } \\
\text { y contenidos recogidos en diversas fuentes }\end{array}$} \\
\hline $\begin{array}{l}\text { COMPETENCIAS } \\
\text { QUE LOS } \\
\text { GERENTES } \\
\text { PROPONEN }\end{array}$ & $\begin{array}{l}\text { CONTENIDOS } \\
\text { QUE LOS } \\
\text { GERENTES } \\
\text { PROPONEN }\end{array}$ & $\begin{array}{l}\text { CONTENIDOS } \\
\text { QUE LOS } \\
\text { TÉCNICOS } \\
\text { PROPONEN }\end{array}$ & $\begin{array}{c}\text { HORIZONTES } \\
\text { PLENA INCLUSIÓN }\end{array}$ & $\begin{array}{l}\text { CÓDIGO DE BUEN } \\
\text { GOBIERNO DEL } \\
\text { MOVIMIENTO } \\
\text { ASOCIATIVO FEAPS }\end{array}$ & $\begin{array}{c}\text { CURSO BÁSICO } \\
\text { DE FORMACIÓN } \\
\text { DE DIRECTIVOS } \\
\text { (PLENA INCLUSIÓN) }\end{array}$ \\
\hline $\begin{array}{l}\text { Visión } \\
\text { estratégica }\end{array}$ & $\begin{array}{l}\text { Estrategia, } \\
\text { visión }\end{array}$ & $\begin{array}{l}\text { Innovación y } \\
\text { creatividad }\end{array}$ & $\begin{array}{l}\text { Horizonte 1: apuesta } \\
\text { radical por la plena } \\
\quad \text { ciudadanía }\end{array}$ & $\begin{array}{l}\text { Principio 1: coherencia } \\
\text { con la misión y el } \\
\text { marco ético de FEAPS }\end{array}$ & $\begin{array}{l}\text { Módulo 1: cultura y } \\
\text { proyecto común del } \\
\text { movimiento asociativo } \\
\text { Plena inclusión } \\
\end{array}$ \\
\hline $\begin{array}{l}\text { Gestión eficaz } \\
\text { y eficiente: }\end{array}$ & Comunicación & $\begin{array}{c}\text { Nuevos } \\
\text { modelos de } \\
\text { negocio y } \\
\text { emprendimiento }\end{array}$ & $\begin{array}{c}\text { Horizonte 2: fomentar } \\
\text { una política de apoyo } \\
\text { a familias desde un } \\
\text { enfoque centrado en } \\
\text { familia }\end{array}$ & $\begin{array}{l}\text { Principio 2: } \\
\text { democracia, } \\
\text { gobernanza y } \\
\text { participación de los } \\
\text { grupos de interés }\end{array}$ & $\begin{array}{l}\text { Módulo 2: } \\
\text { las personas }\end{array}$ \\
\hline $\begin{array}{l}\text { Habilidades } \\
\text { comunicativas }\end{array}$ & $\begin{array}{l}\text { Trabajo en } \\
\text { equipo y } \\
\text { desarrollo de } \\
\text { personas }\end{array}$ & Valores y ética & $\begin{array}{l}\text { Horizonte 3: } \\
\text { reivindicar un nuevo } \\
\text { marco jurídico que } \\
\text { garantice e impulse la } \\
\text { vida de las personas y } \\
\text { la de sus familias }\end{array}$ & $\begin{array}{l}\text { Principio 3: gestión } \\
\text { responsable, honesta y } \\
\text { comprometida con el } \\
\text { proyecto común }\end{array}$ & $\begin{array}{l}\text { Módulo 3: nuestras } \\
\text { organizaciones y el } \\
\text { modelo de organización } \\
\text { que necesitamos }\end{array}$ \\
\hline
\end{tabular}

Ediciones Universidad de Salamanca / CC BY-NC-ND

Siglo Cero, vol. 49 (4), n. ${ }^{\circ}$ 268, 2018, octubre-diciembre, pp. 7-34 


\begin{tabular}{|c|c|c|c|c|c|}
\hline \multicolumn{6}{|c|}{$\begin{array}{c}\text { TABLA 7. Comparativa de las grandes categorías de retos, competencias } \\
\text { y contenidos recogidos en diversas fuentes (cont.) }\end{array}$} \\
\hline $\begin{array}{l}\text { COMPETENCIAS } \\
\text { QUE LOS } \\
\text { GERENTES } \\
\text { PROPONEN }\end{array}$ & $\begin{array}{l}\text { CONTENIDOS } \\
\text { QUE LOS } \\
\text { GERENTES } \\
\text { PROPONEN }\end{array}$ & $\begin{array}{l}\text { CONTENIDOS } \\
\text { QUE LOS } \\
\text { TÉCNICOS } \\
\text { PROPONEN }\end{array}$ & $\begin{array}{c}\text { HORIZONTES } \\
\text { PLENA INCLUSIÓN }\end{array}$ & $\begin{array}{l}\text { CÓDIGO DE BUEN } \\
\text { GOBIERNO DEL } \\
\text { MOVIMIENTO } \\
\text { ASOCIATIVO FEAPS }\end{array}$ & $\begin{array}{l}\text { CURSO BÁSICO } \\
\text { DE FORMACIÓN } \\
\text { DE DIRECTIVOS } \\
\text { (PLENA INCLUSIÓN) }\end{array}$ \\
\hline $\begin{array}{l}\text { Trabajo en } \\
\text { equipo }\end{array}$ & $\begin{array}{l}\text { Orientación a } \\
\text { la excelencia }\end{array}$ & $\begin{array}{c}\text { Desarrollar } \\
\text { persona }\end{array}$ & $\begin{array}{l}\text { Horizonte 5: apostar } \\
\text { por los procesos de } \\
\text { transformación de } \\
\text { entidades y servicios. } \\
\text { Avanzar desde nuestro } \\
\text { sentido de la calidad }\end{array}$ & & $\begin{array}{l}\text { Módulo 5: el papel de } \\
\text { las personas directivas: } \\
\text { liderazgo y poder }\end{array}$ \\
\hline Flexibilidad & $\begin{array}{c}\text { Otros } \\
\text { contenidos }\end{array}$ & $\begin{array}{l}\text { Influencia: } \\
\text { conector y } \\
\text { generador de } \\
\text { alianzas con el } \\
\text { entorno } \\
\end{array}$ & $\begin{array}{l}\text { Horizonte 6: afrontar la } \\
\text { renovación y el cambio } \\
\text { generacional desde una } \\
\text { visión moderna del } \\
\text { asociacionismo }\end{array}$ & & $\begin{array}{l}\text { Módulo 6: procesos y } \\
\text { herramientas para que } \\
\text { las personas directivas } \\
\text { trabajen y avancen: el } \\
\text { futuro }\end{array}$ \\
\hline $\begin{array}{l}\text { Orientación } \\
\text { hacia la } \\
\text { excelencia }\end{array}$ & & $\begin{array}{l}\text { Capacidades } \\
\text { de líder }\end{array}$ & $\begin{array}{l}\text { Horizonte 7: aumentar } \\
\text { la visibilidad social del } \\
\text { colectivo }\end{array}$ & & \\
\hline \multirow[t]{2}{*}{ Entorno } & & $\begin{array}{l}\text { Capacidad para } \\
\text { crear red }\end{array}$ & $\begin{array}{l}\text { Horizonte 8: coordinar } \\
\text { y articular la defensa de } \\
\text { los derechos y nuestra } \\
\text { acción de prestadores } \\
\text { de apoyo }\end{array}$ & & \\
\hline & & $\begin{array}{l}\text { Conocimiento } \\
\text { del medio }\end{array}$ & $\begin{array}{l}\text { Horizonte 9: aumentar } \\
\text { nuestra coordinación y } \\
\text { la acción conjunta para } \\
\text { afrontar los retos en } \\
\text { común }\end{array}$ & & \\
\hline
\end{tabular}

A partir de la comparativa de competencias y contenidos, el equipo de trabajo elaboró una serie de documentos de síntesis que se recogen en los gráficos siguientes y que reflejan, en el primer caso, las dimensiones de las competencias del liderazgo (saber, saber hacer y saber estar) y los niveles en que estas competencias operan (en lo personal -respecto a uno mismo-, respecto a las personas, con los equipos, con la organización y con el mundo).

Partiendo de esta concepción de competencias, en el Gráfico 3 se recogen las propuestas de materias y módulos para la formación de la función directiva en entidades del Movimiento Plena inclusión y el Tercer Sector, articuladas en cinco grandes bloques. En el primero de ellos asume un papel central la reflexión sobre el modelo de desarrollo organizacional, con el desarrollo de competencias para afrontar procesos de cambio. El segundo gran bloque está formado por las competencias y contenidos relacionados con la gestión del cambio (aprendizaje organizacional y gestión estratégica de personas para el cambio). El tercer bloque hace referencia a los procesos de comunicación, trabajo en equipo, gestión de redes, creatividad e innovación. El cuarto bloque a los procesos de planificación de proyectos, gestión económica, gestión de 
TIC, evaluación y mejora; concluyendo con un quinto bloque dedicado íntegramente al análisis del entorno.

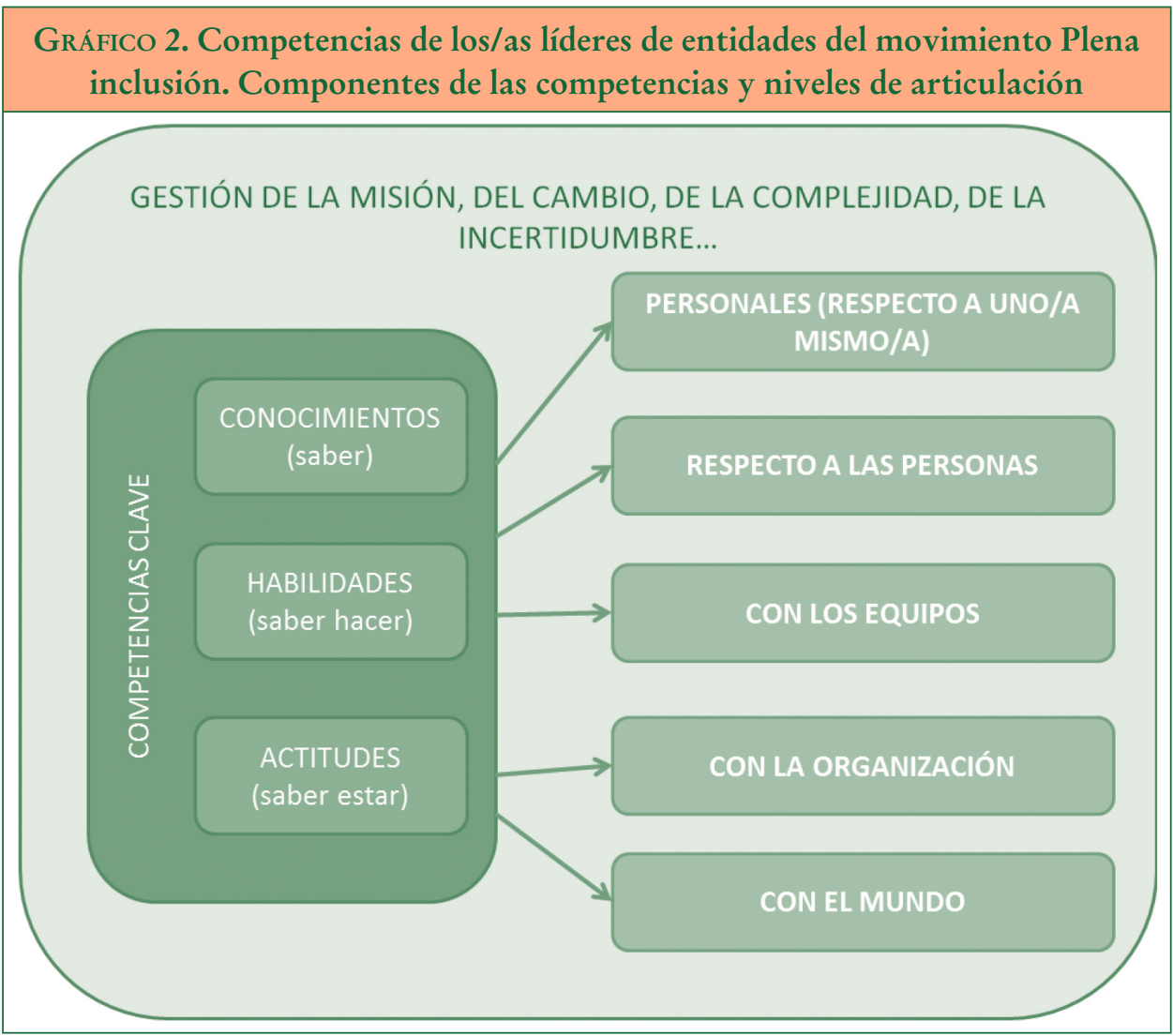

Lógicamente, este modelo de marcos competenciales debería desarrollarse para constituir un listado más o menos completo de competencias de los y las líderes de las entidades para personas con discapacidad y el Tercer Sector. Este trabajo todavía está en proceso, pero se parte, nuevamente, de establecer analogías con el marco universitario, y se parte de las competencias básicas que según el Real Decreto 1393/2007, de 29 de octubre, por el que se establece la ordenación de las enseñanzas universitarias oficiales, se consideran específicas de un nivel de máster que, como se dijo anteriormente, es el referente que quiere asumir la formación de los y las líderes profesionales en Plena inclusión. Estas competencias básicas quedan reflejadas de la siguiente manera en el artículo 3.3 del citado Real Decreto:

1. Poseer y comprender conocimientos que aporten una base $u$ oportunidad de ser originales en el desarrollo y/o aplicación de ideas, a menudo en un contexto de investigación; 


\section{GráfICO 3. Propuesta de materias y módulos para la formación de la función directiva en líderes profesionales en entidades del movimiento asociativo Plena inclusión}

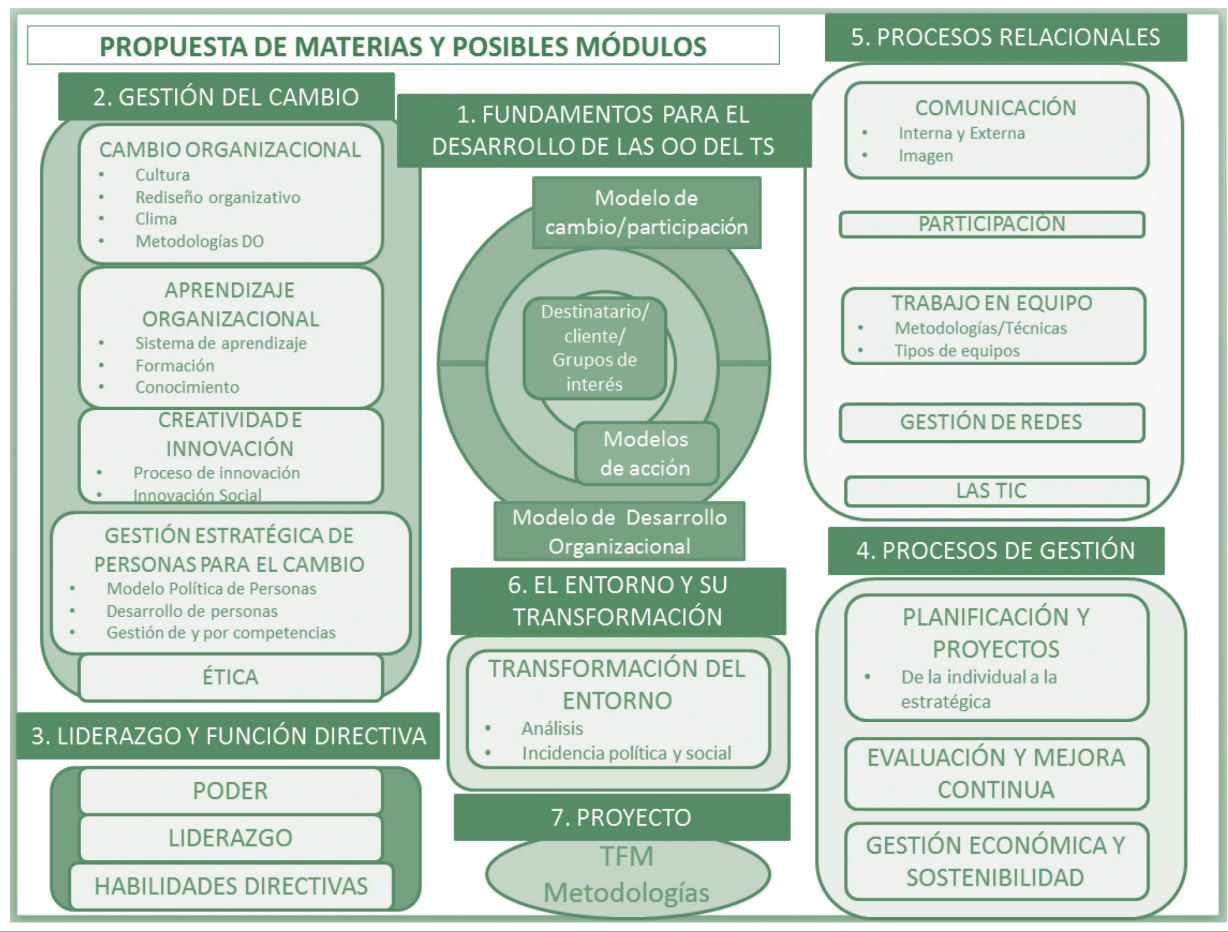

2. Que los estudiantes sepan aplicar los conocimientos adquiridos y su capacidad de resolución de problemas en entornos nuevos o poco conocidos dentro de contextos más amplios (o multidisciplinares) relacionados con su área de estudio;

3. Que los estudiantes sean capaces de integrar conocimientos y enfrentarse a la complejidad de formular juicios a partir de una información que, siendo incompleta o limitada, incluya reflexiones sobre las responsabilidades sociales y éticas vinculadas a la aplicación de sus conocimientos y juicios;

4. Que los estudiantes sepan comunicar sus conclusiones -y los conocimientos y razones últimas que las sustentan-a públicos especializados y no especializados de un modo claro y sin ambigüedades;

5. Que los estudiantes posean las habilidades de aprendizaje que les permitan continuar estudiando de un modo que habrá de ser en gran medida autodirigido o autónomo.

De manera complementaria a estas competencias, y con carácter todavía de borrador, se elaboró un listado de competencias derivado de la síntesis de los trabajos de 
gerentes y personal técnico, así como el análisis de la documentación de referencia, utilizando la lógica adoptada y antes descrita de la estructura de los tres tipos de competencias en cuanto a conocimientos, habilidades y actitudes, en cada uno de los niveles, desde el personal pasando por las personas, los equipos, las redes, la organización y el entorno. En las Tablas 8, 9 y 10 se recoge este listado de competencias recordando, nuevamente, su condición de provisional. 
AVANCES EN EL LIDERAZGO: MARCO DE COMPETENCIAS DE LOS LÍDERES PROFESIONALES

F. J. GÓMEZ GONZÁLEZ, J. J. LACASTA REOYO, V. A. MARTÍNEZ-TUR Y C. RODRÍGUEZ SUMAZA

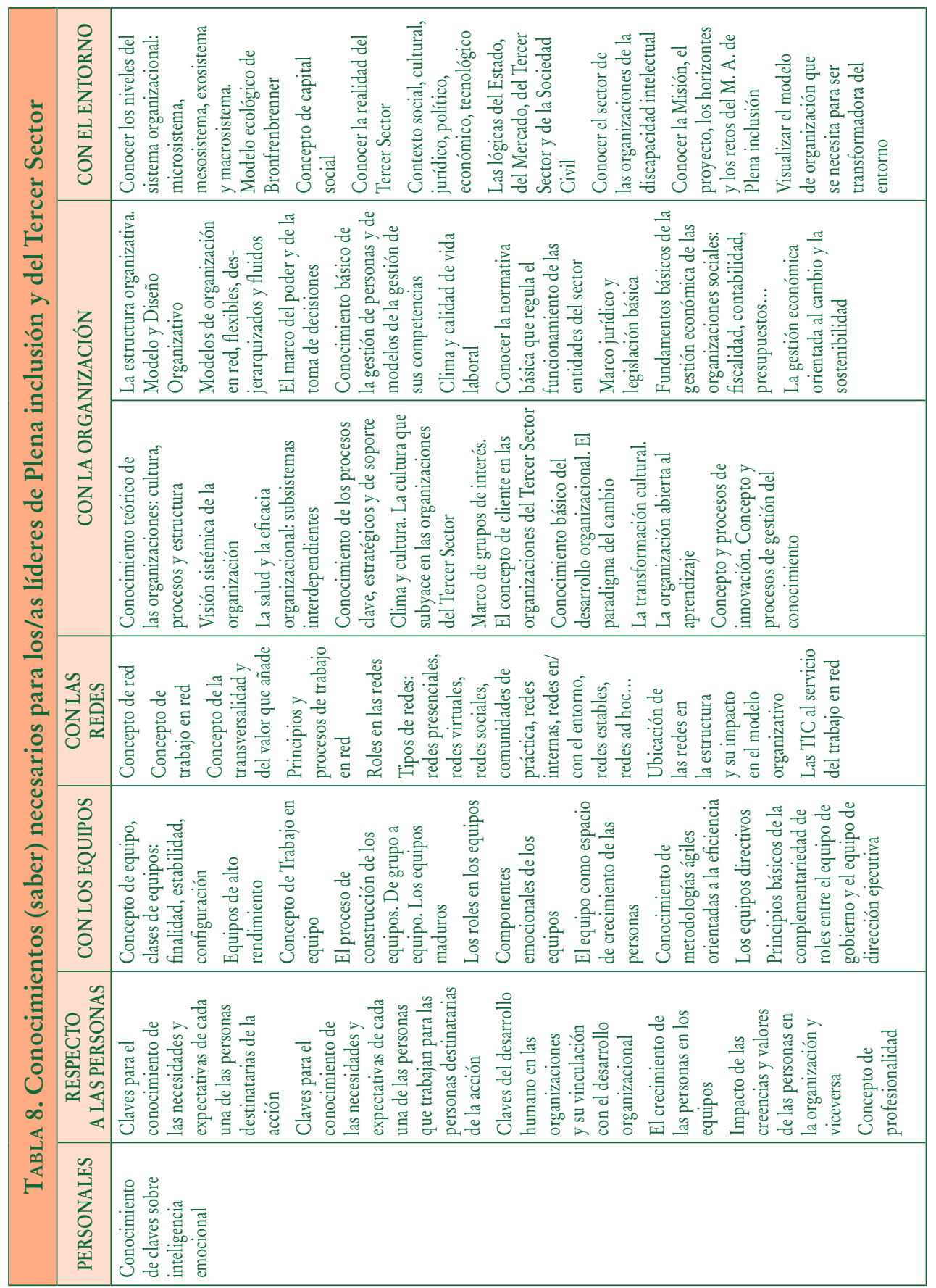

Ediciones Universidad de Salamanca / CC BY-NC-ND

Siglo Cero, vol. 49 (4), n. ${ }^{\circ}$ 268, 2018, octubre-diciembre, pp. 7-34 


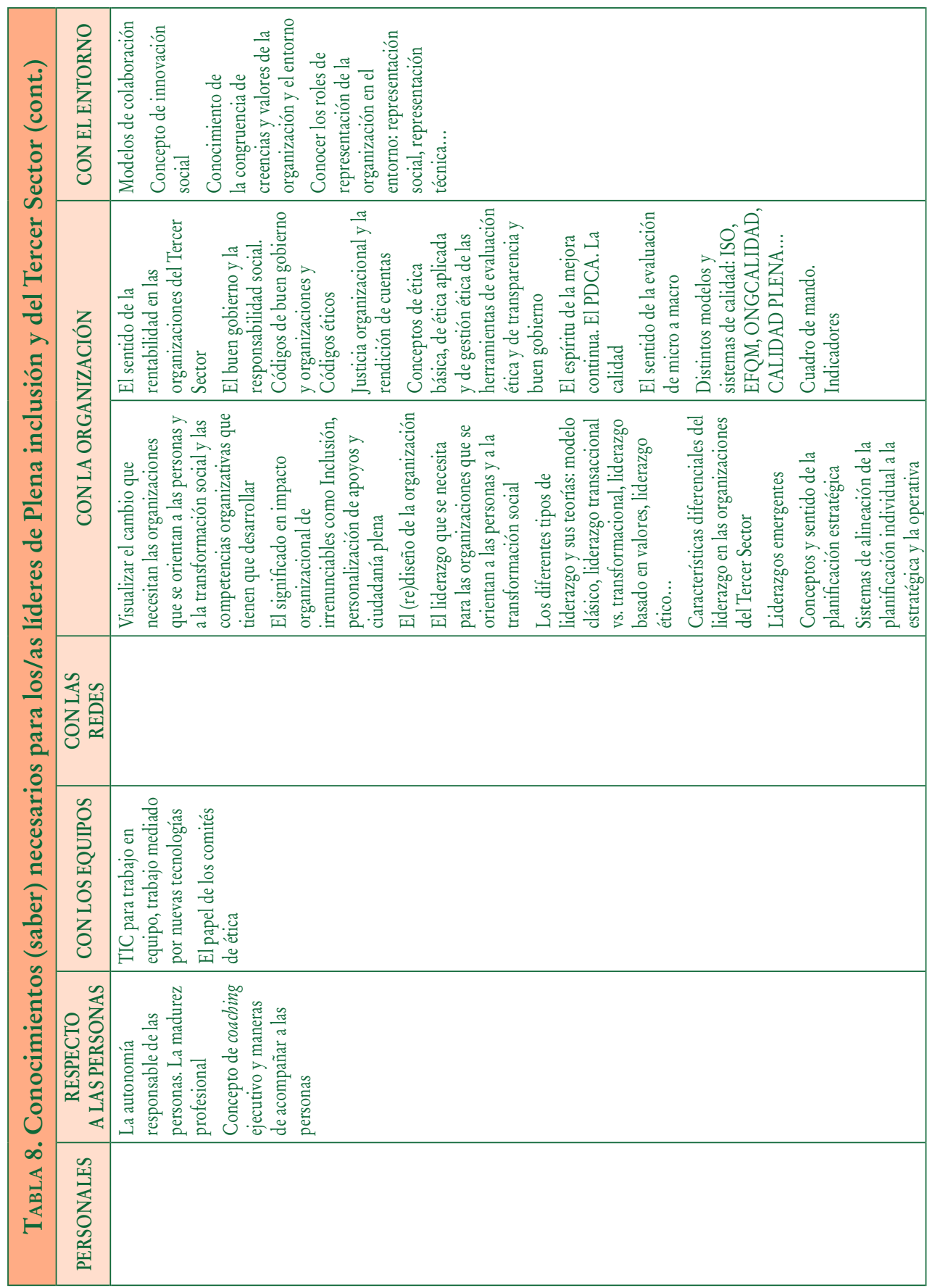

Ediciones Universidad de Salamanca / CC BY-NC-ND

Siglo Cero, vol. 49 (4), n. ${ }^{\circ}$ 268, 2018, octubre-diciembre, pp. 7-34 
AVANCES EN EL LIDERAZGO: MARCO DE COMPETENCIAS DE LOS LÍDERES PROFESIONALES

F. J. GÓMEZ GONZÁLEZ, J. J. LACASTA REOYO, V. A. MARTÍNEZ-TUR Y C. RODRÍGUEZ SUMAZA

\begin{tabular}{|c|c|c|}
\hline 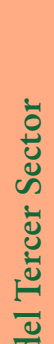 & 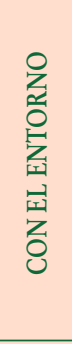 & 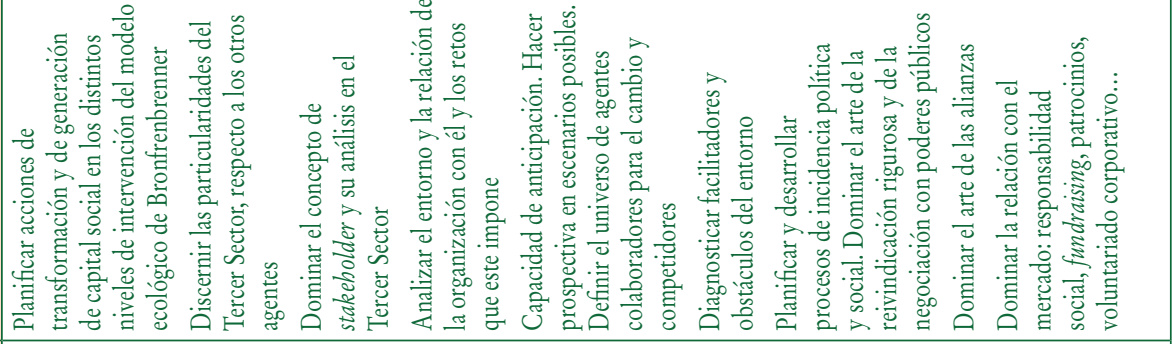 \\
\hline & 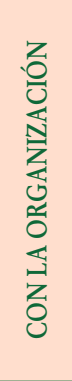 & 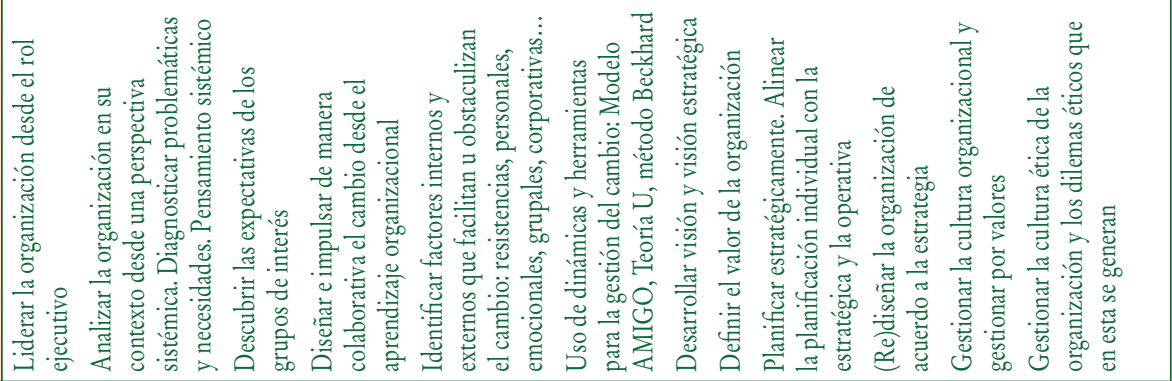 \\
\hline 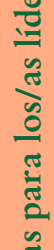 & 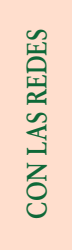 & 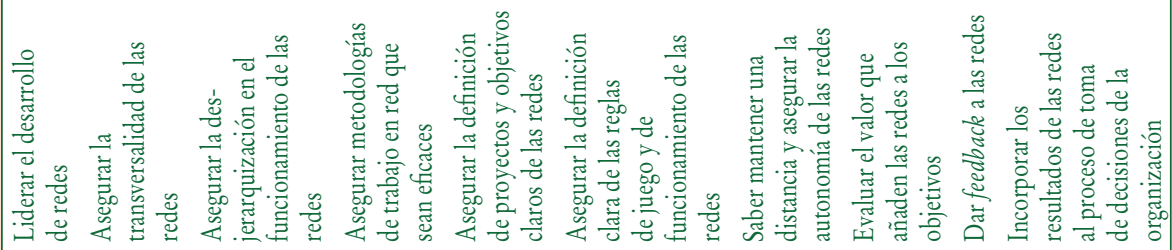 \\
\hline 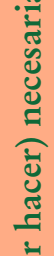 & 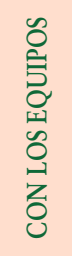 & 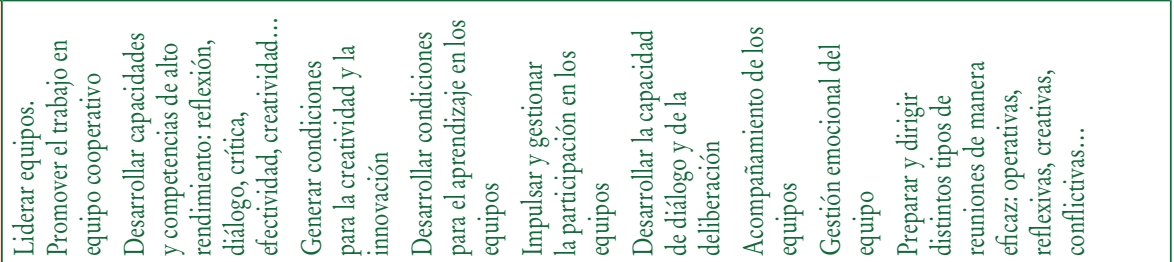 \\
\hline 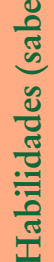 & 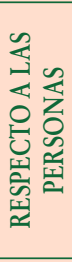 & 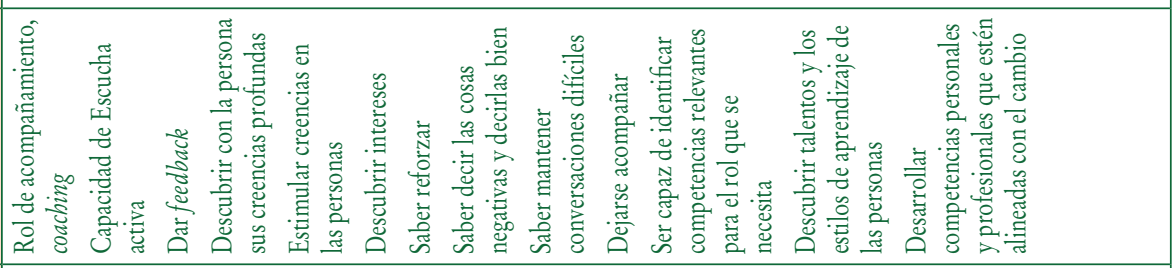 \\
\hline 家 & 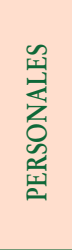 & 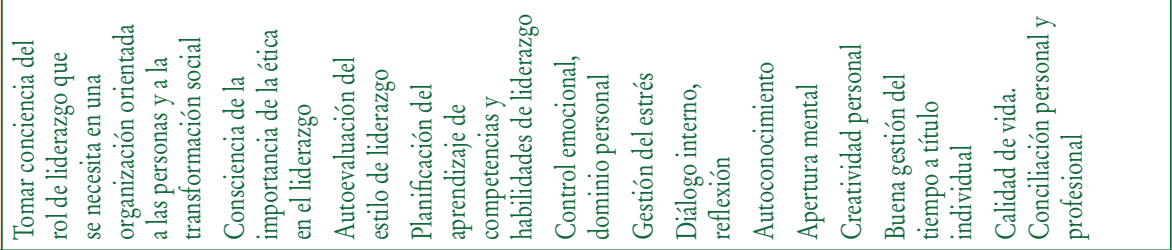 \\
\hline
\end{tabular}

Ediciones Universidad de Salamanca / CC BY-NC-ND

Siglo Cero, vol. 49 (4), n. ${ }^{\circ}$ 268, 2018, octubre-diciembre, pp. 7-34 
AVANCES EN EL LIDERAZGO: MARCO DE COMPETENCIAS DE LOS LÍDERES PROFESIONALES

F. J. GÓMEZ GONZÁLEZ, J. J. LACASTA REOYO, V. A. MARTÍNEZ-TUR Y C. RODRÍGUEZ SUMAZA

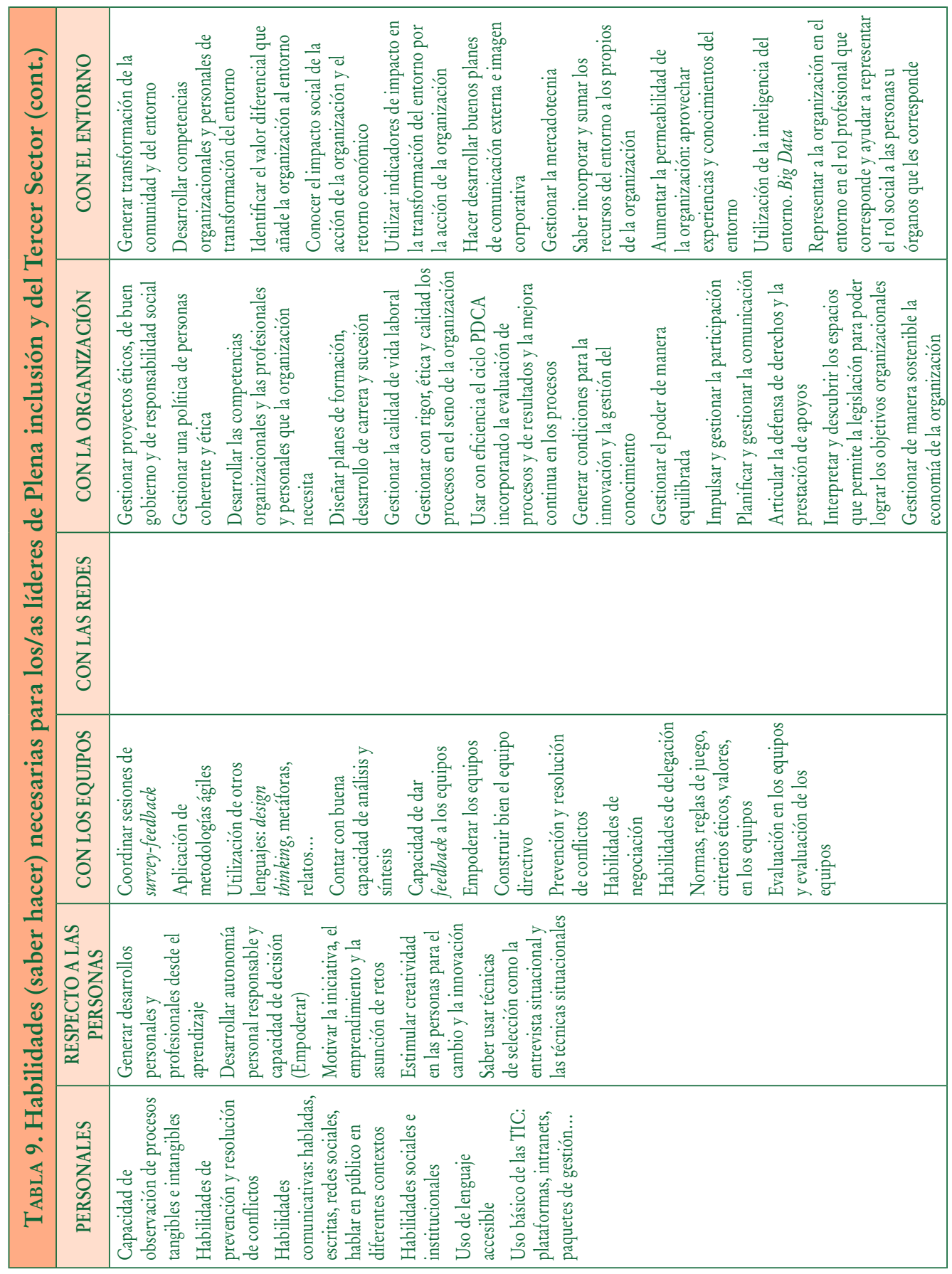

Ediciones Universidad de Salamanca / CC BY-NC-ND

Siglo Cero, vol. 49 (4), n. ${ }^{\circ}$ 268, 2018, octubre-diciembre, pp. 7-34 


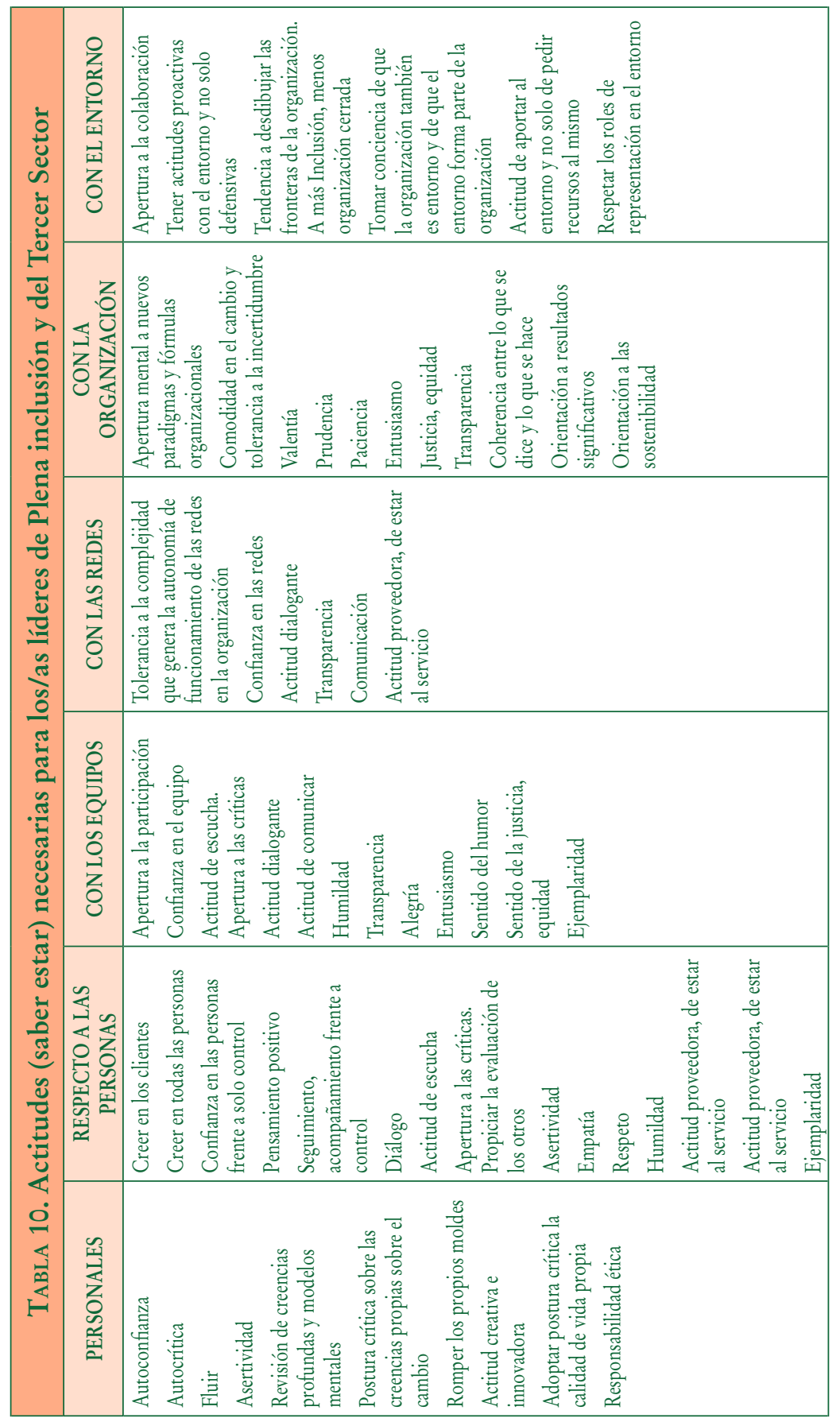

Ediciones Universidad de Salamanca / CC BY-NC-ND

Siglo Cero, vol. 49 (4), n. ${ }^{\circ}$ 268, 2018, octubre-diciembre, pp. 7-34 


\section{Conclusiones}

El presente trabajo ha descrito y analizado la dinámica de elaboración de un marco de competencias para líderes de Plena inclusión y del Tercer Sector. Durante este proceso se han desarrollado aprendizajes de utilidad tanto para estas instituciones como para otros sectores y entornos institucionales. A continuación, se detallan algunos de ellos, expresados a modo de conclusión:

En primer lugar, es importante señalar la pertinencia de utilizar una diversidad de técnicas y de fuentes de información para definir competencias. De hecho, el éxito de esta tarea exige la integración de fuentes documentales, reflexiones prospectivas, análisis de las fuentes bibliográficas sobre función directiva y, sobre todo, dinámicas de trabajo participativo. Dentro de estas fuentes de información, el equipo considera como fundamentales las metodologías participativas y, especialmente, la recogida de información de manera directa de mano de los/as líderes profesionales, así como de los perfiles técnicos.

Este trabajo participativo desarrollado en un contexto de diálogo y flexibilidad comunicativa ha permitido estructurar los niveles de actuación de las competencias (personal, interpersonal, grupal, organizativo y con el contexto), así como sus tres dimensiones (saber, saber hacer y saber ser). Esta articulación en niveles es plenamente coherente con los modelos de interpretación de las organizaciones defendidos por los teóricos de la escuela de Desarrollo Organizacional.

Los resultados competenciales permiten comprobar las singularidades que presentan los y las líderes del Tercer Sector respecto a otros contextos y otros marcos organizativos, siendo una apuesta de los autores el mantener esta singularidad, potenciando sus fortalezas y eliminando los enfoques o pautas de actuación que se hayan demostrado poco eficaces.

Para concluir, simplemente señalar que la información recopilada permitirá, sin duda, el diseño de un programa formativo, pertinente, a medida, viable y con potencial transformador, que se ofrecerá a miembros de las organizaciones de Plena inclusión y del Tercer Sector.

Es necesario apuntar que, a pesar de que el estudio nace con una clara vocación aplicada a la realidad organizativa de Plena inclusión, también pretende aportar datos para el diseño de perfiles competenciales en otras organizaciones. Para facilitar la aplicación en otros contextos es fundamental continuar ampliando la base empírica del estudio, incluyendo nuevas organizaciones del Tercer Sector, manteniendo el rigor metodológico para, de esta manera, incrementar la validez de los resultados reflejados en el presente artículo.

\section{Referencias bibliográficas}

CEDEFOP (2016). Directrices europeas para la validación del aprendizaje no formal e informal. Luxemburgo: Oficina de Publicaciones.

Cover, S. R. (2004). Los tres papeles que desempeña el líder en el nuevo paradigma. En F. Hesselbein, M. Goldsmith y R. Beckhard (Coords.), El líder del futuro (pp. 177-188). Barcelona: The Drucker Foundation, Ed. Deusto. 
Dym, B. y Hutson, H. (2005). Leadership in nonprofit organizations. Thousand Oaks, CA: SAGE Publications.

FEAPS (1997). I Plan Estratégico de FEAPS. FEAPS.

FEAPS (2002). II Plan Estratégico (2002-2005). FEAPS.

FEAPS (2006). III Plan Estratégico de FEAPS (2006-2009). FEAPS.

FEAPS (2010). IV Plan Estratégico FEAPS (2011-2014). FEAPS.

FEAPS (2014). Código de Buen Gobierno del Movimiento Asociativo FEAPS. FEAPS.

González, J. y WagenaAR, R. (2006). Tuning Educational Structures in Europe. II. La contribución de las universidades al Proceso de Bolonia. Bilbao: Universidad de Deusto y Universidad de Groningen.

Hesselbein, F., Goldsmith, M. y Beckhard, R. (2004). El líder del futuro. Barcelona: The Drucker Foundation, Ed. Deusto.

Hines, A. y Bishop, P. (2007). Thinking about the future. Guidelines for Strategic Foresight. Washington, DC: Social Technologies.

Kouzes, J. M. y Posner, B. Z. (2004). Siete lecciones para liderar el viaje hacia el futuro. En F. Hesselbein, M. Goldsmith y R. Beckhard (Coords.), El líder del futuro (pp. 130-141). Barcelona: The Drucker Foundation, Ed. Deusto.

Lacasta, J. J. (1998a). Calidad organizacional: el cambio en las organizaciones no gubernamentales. Siglo Cero, 29 (1), 5-13.

LACASTA, J. J. (1998b). El cambio en las organizaciones no gubernamentales a favor de las personas con retraso mental. Servicios Sociales y Política Social, 42, 9-22 (Ejemplar dedicado a: Discapacidad psíquica y calidad de vida I).

LAcASTA, J. J. (2002). La experiencia de FEAPS en el proceso de implantación de la calidad: o el esfuerzo de un sector por situarse en nuevos paradigmas. Documentación Social, 128, 291 304 (Ejemplar dedicado a: La calidad como imperativo en la acción social).

Le Boterf, G. (2001). Ingeniería de las competencias. Barcelona: Gestión 2000.

LÉvy-Levoyer, C. (1997). Gestión de competencias. Cómo analizarlas, cómo evaluarlas, cómo desarrollarlas. Barcelona: Gestión 2000.

Mateo, J., Escofet, A., Martínez-Olmo, F., Ventura, J. y Vlachopoulos, D. (2012). Evaluation tools in the European Higher Education Area (EHEA): an assessment for evaluating the competences of the Final Year Project in the social sciences. European Journal of Education, 47 (3), 435-447.

McClelland, D. C. (1973). Testing for competence rather than for 'intelligence'. American Psychologist, 28 (1), 1-14.

Mintzberg, H. (2013). Managers not MBAs: a hard look at the soft practice of managing and management development. San Francisco: Berrett-Koehler Publishers.

Mulder, M. (2007). Competencia: la esencia y la utilización del concepto en la formación profesional inicial y permanente. Revista Europea de Formación Profesional, 40 (1), 5-24.

Plena inclusión (2016). V Plan Estratégico 2016-2020. Plena inclusión.

Prahalad, C. K. y Hamel, G. (1990). The core competence of the corporation. Harvard Business Review, may-june, 79-91.

Schalock, R. L. (2015). Las mejores prácticas de las organizaciones y los profesionales. Siglo Cero, 46 (1), 7-23.

TAMARIT, J. (2015). La transformación de los servicios hacia la calidad de vida. Una iniciativa de innovación social de FEAPS. Siglo Cero, 46 (3), 47-71.

Tirmizi, S. A. y Vogelsang, J. D. (2017). Leading and managing in the social sector. Strategies for advancing human dignity and social justice. Cham, Switzerland: Springer International Publishing. 